\title{
High crosslinked sodium carboxyl methylstarch-g-poly (acrylic acid-co-acrylamide) resin for heavy metal adsorption: its characteristics and mechanisms
}

\author{
Ming Zhang ${ }^{1}$ \& Ping Yang ${ }^{1}$ \& Guihong Lan $^{2}$ \& Yongqiang Liu $^{3}$ \& Qin Cai ${ }^{1}$ \& Junnan Xi ${ }^{2}$ \\ 1 College of Architecture and Environment, Sichuan University, Chengdu 610065, China \\ 2 College of Chemistry and Chemical Engineering, Southwest Petroleum University, Chengdu 610500, People's Republic of China \\ 3 Faculty of Engineering and Physical Sciences, University of Southampton, Southampton SO17 1BJ, UK
}

\begin{abstract}
A lower expansive heavy metal adsorbent, high crosslinked sodium carboxyl methylstarch-g-poly (acrylic acid-co-acrylamide) resin (HCAA), has been prepared by enhancing the crosslinking degree of the traditional water-absorbing polymer under the graft copolymerization reaction. Further heavy metal adsorption experiments, morphology analysis, and structure characteristicobservations indicate that HCAA resin has an excellent heavy metal adsorption properties for $\mathrm{Cr}^{3+}, \mathrm{Cu}^{2+}, \mathrm{Ni}^{2+}$, and $\mathrm{Zn}^{2+}$ of 80.08 , 158.07, 155.71, and $137.15 \mathrm{mg} / \mathrm{g}$, respectively. The nanoholes in network structures of HCAA resin expanding in solution provide an effective diffusion and exchange channels for heavy metal ions and $\mathrm{Na}^{+}$. The adsorption process of HCAA containing - $\mathrm{COONa}$ is attributed to ion exchange process, and its essence is to form the coordination bond with heavy metals. The adsorption capacity differences of $-\mathrm{COO}^{-}$have been explained by using the coordination chemistry theory. In addition, the adsorption selectivity of an expansive adsorbent containing-COONa are heavy metals $>\mathrm{H}_{2} \mathrm{O}>>\mathrm{Na}^{+}$. Our research puts forward an insight that increasing the crosslinker content on the basis of the traditional super absorbent resin can obtain a lower expansive adsorbent to heavy metal pollutants.
\end{abstract}

Keywords Heavy metal adsorption $\cdot$ Expansive adsorbent $\cdot$ Mechanism $\cdot$ Carboxylic group $\cdot$ Ion exchange

\section{Introduction}

Environmental pollution containing heavy metal ions in wastewater or soils has increasingly become a widely con- cerned topic because of its non-biodegradability and high tox- icity. In the natural environment, heavy metal pollutants can only be transported from water or soils into the organisms, accompanied by the chemical morphologic transformation, including exchangeable, carbonate-bound, metal-organic complex-bound metals, and so on (Fiyadh et al. 2019; Hossain et al. 2012). Long-term accumulation of heavy metals has a potential harm to organism health. Thus, various tech- niques, such as chemical precipitation, membrane separation, biotransformation, and adsorption, have been applied to re- duce the heavy metal concentration before discharge (Gupta and Nirwan 2015; Gao et al. 2019a; b; Matlock et al. 2002; Uddin 2017). Among them, only adsorption is very which can completely adsorb and enrich the heavy metal pollutants from the contaminated sites due to its high selectivity and simple separability. In addition, desorption experiment to evaluate reusability of the adsorbent is usually performed in acid, alkali, or salt solutions, which will also cause a second- ary pollution and extra difficulties in disposing the eluates. To balance the cost, simplicity, reliability, and secondary pollu- tion problem, better treatment for adsorbents of saturated ad- sorption is ashed to recycle or landfilled to harmless disposal. Specifically, the fixed-bed adsorption has been employed in wastewater treatment or metal recovery based on its rapidity and continuity. Thus, filler in equipment is of critical impor- tance to ensure that the pollutant concentration in purified water meets the discharge standards. So, extensive researches have been conducted to develop low-cost and high- performance adsorbents via the modification of natural mate- rials or improvement of synthesis method (Almughamisi et al. 2020; Elgarahy et al. 2020; Elwakeel et al. 2020).

Furthermore, the adsorbents can adsorb heavy metal ions firmly because of its contained adsorption functional groups, the low-cost adsorbent with these reagents can be obtained by enhancing the crosslinking density of the traditional SAR. Moreover, previous studies have focused on the development of new materials to enhance heavy metal adsorption capacity and abandon the original exploration of the adsorption mech- anism. So, from our experiments, the adsorption mechanism and process were explained from the basic principles of the functional adsorption sites.

In the present study, we took advantage of the CMS and such as $-\mathrm{COO}^{-}$and $-\mathrm{SO}_{3}$ (Liu et al. 2019; Liu et al. 2020; AA chemical structures with carboxyl groups to synthesize a 
Vakili et al. 2019). In addition, the adsorbents are partially similar with a new functional polymer with highly insolubility character, called super absorbent resin (SAR), which have numerous hydrophilic groups, such as $-\mathrm{COO}^{-}$and $-\mathrm{OH}$, and can conserve water at hundreds or even thousands of its weight. Meanwhile, in our previous research to obtain SAR by soluble starch and acrylamide under the graftcopolymeriza-

tion and hydrolysis reaction, we found that the water absor- bency of SAR was inversely related with the crosslinker concentration and the increase of the crosslinker concentration resulted in the decrease of water absorbency (Lan et al. 2019). Based on the observation, we put forward a hypothesis that increasing the crosslinker content enormously can greatly hinder the water-absorbing expansibility of SAR, which might be conducive to material transfer process and make polymer falls back on excellent heavy metal adsorption capacity.

Sodium carboxyl methylstarch (CMS), a starch derivative composed of two $-\mathrm{OH}$ and one $-\mathrm{COO}^{-}$groups in sixmembered ring structure units, is produced by chloroacetic acid-modified starch under bimolecular nucleophilic substitu- tion in alkaline conditions, which has greater solubility and biodegradability. So, modified CMS does possess the interacting property and thus can be applied to adsorb heavy metal ions. However, the utilization of CMS to develop heavy metal adsorbent is seldom reported. Similarly, acrylic acid (AA), a vinyl monomer consisting of the -COOH group, is suitable as starting material to synthesize the polymers with high molecular weight (Lu et al. 2012). Acrylamide (AM), a vinyl monomer, is also added to enhance the hydrogel strength and increase the molecular weight of target polymer. In order to reduce the acidity of the polymerized system and make it graft with other monomers easier, the neutralization of AA is usually adjusted by adding alkali. This conversion of - $\mathrm{COOH}$ into - COONa has the coordinate effect with heavy metal ions based on the long pair electrons of atomic oxygenin $-\mathrm{COO}^{-}$groups. Meanwhile, those hydrophilic monomers can be connected together to synthesize a new polymer by graft copolymerization reaction in the solution by adding the initiator, such as persulfate, hydroperoxide, and so on, to cre- ate free radicals to transform the monomers into a high mo- lecular polymer with long chains. The significant distinction between adsorbent and the conventional water-soluble poly- mer is to introduce the crosslinker to make it insoluble. Thus,high crosslinked sodium carboxyl methylstarch- $g$-poly (acryl- ic acid-coacrylamide) resin to adsorb heavy metal ions. We studied the influence of the crosslinker contents to the expan- sibility and the mechanical properties (including storage and loss modulus) of the resin. And then based on the optimized crosslinker contents to hinder the water absorbency of the polymer, the heavy metal adsorption properties and mecha- nisms of the obtained resin were fully investigated.

\section{Experimental}

\section{Materials}

Sodium CMS was purchased from Cool Chemical Technology Corporation Ltd. (Beijing, China). AM, AA, ammonium persulfate (APS), $N, N$-methylene bisacrylamide (MBA), sodium hydroxide $(\mathrm{NaOH})$, copper sulfate $\left(\mathrm{CuSO}_{4}\right)$, chromium chloride $\left(\mathrm{CrCl}_{3}\right)$, nickel chloride $\left(\mathrm{NiCl}_{2}\right)$, and zinc sulfate $\left(\mathrm{ZnSO}_{4}\right)$ were all of analytical reagent grade and purchased from Kelong Chemical Reagent Plant (Chengdu, China).

\section{Synthesis of CMS-g-poly (AA-co-AM) resin}

Sodium carboxyl methylstarch-g-poly (AA-co-AM) resin was synthesized in aqueous solution through graft polymerization by using APS as the initiator and MBA as the crosslinking agent. Firstly, acrylic acid $(5.0 \mathrm{~mL})$ and sodium hydroxide (concentration of $10 \mathrm{wt} . \%$ ) were mixed in a $100-\mathrm{mL}$ beaker to adjust the neutralization degree of acrylic acid into $100 \%$, which was equipped with a magnetic stirring apparatus at $70{ }^{\circ} \mathrm{C}$. Then acrylamide $(1.0 \mathrm{~g})$, sodium carboxyl methylstarch $(3.0 \mathrm{~g})$, and various amounts of MBA $(0 \mathrm{~g}$ to

$0.40 \mathrm{~g}$ with an interval of $0.05 \mathrm{~g}$, dispersed in $10 \mathrm{~mL}$ deionized water) were added into the beaker, in which the mixed solution was kept stirred for 10 min to make starch molecules swollen. After that, the $\mathrm{pH}$ of the mixed solution was adjusted to neutral with $1 \mathrm{~mol} / \mathrm{L} \mathrm{NaOH}$, and the predissolved APS solution ( $0.25 \mathrm{~g}$ APS dispersed in $5 \mathrm{~mL}$ deionized water) was then added. After a few minutes, the mixed solution changed to a gel status, so the magnetic stirrer was switched off and the temperature was maintained for 1 after the 
reaction. Finally, the large block hydrogel was cut into gran- ular gel and dried at $70{ }^{\circ} \mathrm{C}$. Moreover, the particulates were milled and sifted through an 18- and 40-mesh sieve, and the intermediate particulates of two sieves were CMS- $g$-poly (AAco-AM) resin with a size of $0.45-1 \mathrm{~mm}$. Specifically, the resin of different crosslinking degree were obtained by changing the amount of MBA in the polymerized system.

\section{Characterization}

Fourier transform infrared (FT-IR) spectrum result was ob- tained from WQF 520 FT-IR spectrometer (Beijing Rayleigh Analytical Instrument Corporation, China) using $\mathrm{KBr}$ discs. The mechanical characteristics of the polymerized gels (size, 1 $\mathrm{cm} \times 1 \mathrm{~cm})$, including storage modulus $\left(G^{\prime}\right)$ and loss mod- ulus $\left(G^{\prime \prime}\right)$, were investigated in HAAKE MARS III Rheometer (HAAKE, Germany) by parallel plate shearing methods under a shearing frequency over the range of 0.10 to $10 \mathrm{~Hz}$. Scanning electron microscopy (SEM) images were obtained from Apreo microscope(FEI, America) coated with Au vapor. The particulates that adsorbed heavy metal ions were dehydrated in gradient ethanol and dried in a supercritical carbon dioxide extraction treatment. The apparent morpholo- gy to HCAA resin in each phase of the heavy metal adsorption process was observed in Zeiss Stemi SV 11 reflected-light microscope (Shanghai, China) under a ×6 magnification.

\section{Water absorbency and heavy metal adsorption measurement}

The water absorbency of CMS- $g$-poly (AA-co-AM) resin with different crosslinking degrees in the deionized water was determined, and the method was referred to a literature (Lan et al. 2019). Moreover, the heavy metal adsorption ca- pacity and mechanisms of the optimized resin product were observed in four solutions, including $\mathrm{CrCl}_{3}, \mathrm{CuSO}_{4}, \mathrm{NiCl}_{2}$, and $\mathrm{ZnSO}_{4}$ with a concentration of $200 \mathrm{mg} / \mathrm{L}$. In more

details, heavy metal solutions (including $\mathrm{Cr}^{3+}, \mathrm{Cu}^{2+}$,

$\mathrm{Ni}^{2+}$, and $\mathrm{Zn}^{2+}$ ) with a concentration of $200 \mathrm{mg} / \mathrm{L}$ wereprepared, where $0.05 \mathrm{~g}$ of the resin was mixed with $50 \mathrm{~mL}$ of the solution at $25{ }^{\circ} \mathrm{C}, 180 \mathrm{rpm}$. After saturation, the heavy metal and $\mathrm{Na}^{+}$concentrations of the residual solution were detected using AA-7020 flame adsorption atomic spectrophotometer (AAS, Beijing City East and West Electronic Technology Institute, China). The adsorp- tion capacity $\left(Q_{\mathrm{a}}\right)$ was calculated according to Eq. (1):

$\underline{\partial C_{0}}-C P X V$ volume of the heavy metal solution (L); and $m$ is the weight of resin particulates $(\mathrm{g})$.

\section{Results and discussion}

\section{Effect of crosslinking degree on expansibility of theresin}

Figure 1 shows that the content of crosslinking agent MBA greatly influenced the expansibility of CMS-g-poly (AA-coAM) resin, where the increase in MBA content caused the decrease of the swelling capacity of the resin particulates. All monomers, including CMS, AA, and AM, do not become an elastic gel but a colloid with a low viscosity when adding the initiator, but no crosslinker, and the uncrosslinked polymer is finally dissolved in the deionized water. However, after introducing MBA to the polymerized system, the crosslinked polymer could not be dissolved in the solution but instead swell and absorb water molecules. During the process of the graft copolymerization reaction, all predissolved monomers could generate free radicals to graft with other monomers under the action of the initiator APS, which could be convert- ed to a series of long chain molecules (Gao et al. 2019a; b). Thereafter, in the presence of the crosslinking agent MBA, there are lots of crosslinking sites that can translate long chain molecules into a network structure and lead the polymerized products to be insoluble in the solution (Soto et al. 2015). The water absorbency of resin decreased from 189.27 to $71.75 \mathrm{~g} / \mathrm{g}$ when MBA contents increased from 0.55 to 1.11 wt.\%. Further increasing MBA contents, the water absorbency of the polymerized resin decreased linearly. When the MBA content was $4.44 \mathrm{wt} . \%$, the water absorbency of the product in the deionized water was $39.74 \mathrm{~g} / \mathrm{g}$. These observations are associated with the crosslinking density of the polymer, which is controlled by the crosslinker concentration. The increase in crosslinking sites between the numerous linear molecules al- lows the gel to obtain a high crosslinking density, which also augments the stretching resistance of the polymer chains and results in the reduction of the expansibility of the resin (Hong et al. 2019).

In order to better explain these phenomena and gain the optimal synthesis condition, the polymerized resins with different crosslinker contents were subjected to rheological ex- periments and presented in Fig. 2 . The MBA contents greatly influence the storage $\left(G^{\prime}\right)$ and loss modulus $\left(G^{\prime \prime}\right)$ of the hydro- gel, which are directly related to the elasticity and viscidity of the
the polymectively. 
where $Q_{\mathrm{a}}$ is the adsorption capacity of the resin (mg/g); $C_{0}$ and $C$ are the heavy metal concentrations of the solution before and after adsorption, respectively (mg/L); $V$ is the further reveals that $G^{\prime}$ of the crosslinked polymers obviously increased with the increase of the MBA dosages, $G^{\prime \prime}$ of the crosslinked polymers initially decreased and then increased

Fig. 1 Effect of MBA content on water absorbency of CMS- $g$-poly (AA-CO-AM)

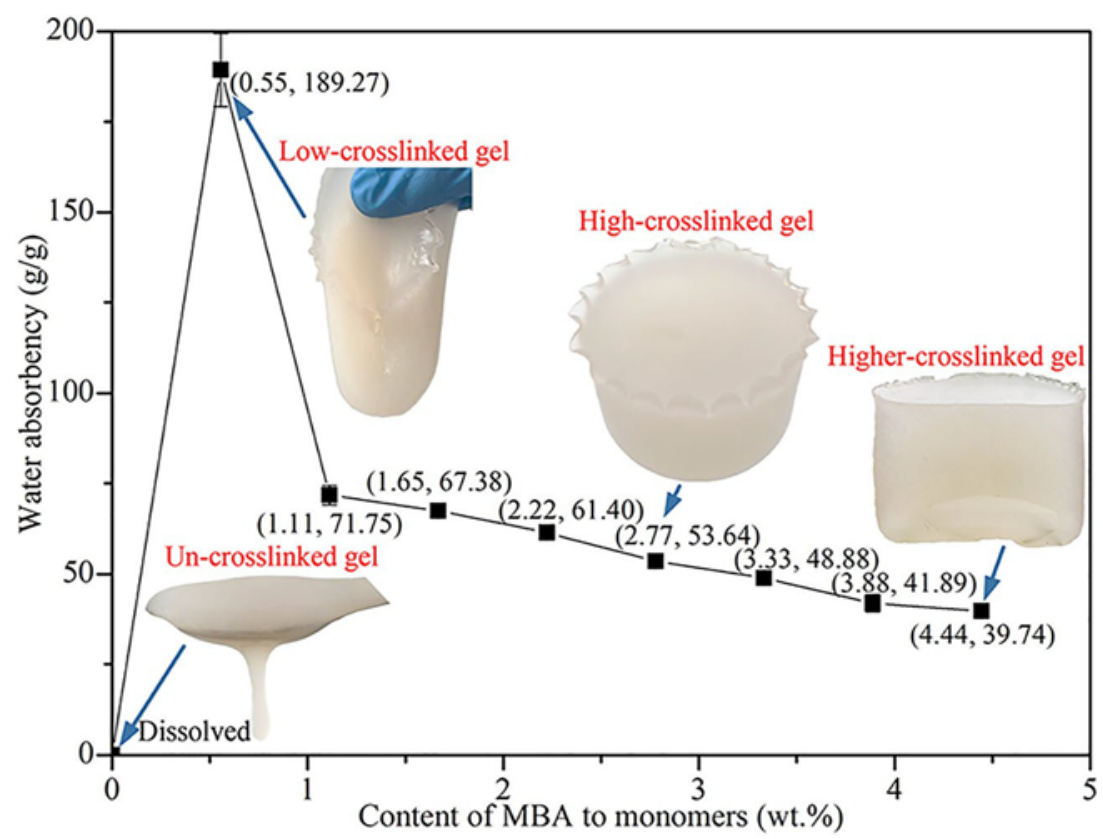

with MBA dosages. When the content of MBA to all mono- mers was $2.77 \mathrm{wt} . \%$, the inflection point of $G^{\prime \prime}$ was obtained. Increasing MBA contents from 0.55 to $2.77 \mathrm{wt} . \%$, the viscid- ity of the polymerized products were decreased and the elasticity were enhanced inversely. However, by continuing to increase MBA dosages, the gel status suddenly became fragile because of the very high crosslinking density.

In addition, extensive researches have already been con- ducted to develop more superior and environmentally friendly SAR, which are shown in Table 1. Many hydrophilic com- pounds, such as chitosan, cellulose, $\beta$-cyclodextric, and starch, have been modified to synthesize SAR by graft poly- merization with AA and AM, which have an excellent water absorbency of 133 to $3050 \mathrm{~g} / \mathrm{g}$. However, these polymers all have a lower crosslinker concentration from 0.04 to 2.0 wt.\% to all monomers. Therefore, based on the similar carboxyl groups between SAR and heavy metal adsorbents and to bal- ance the expansibility and hydrogel strength (including the viscidity, elasticity and brittleness), the MBA content of CMS-g-poly (AA-co-AM) resin is found to account for

$2.77 \mathrm{wt.} \%$ to all monomers in the following heavy metal ad- sorption experiments. The optimal conditions for HCAA resin preparation are as follows: $3 \mathrm{~g}$ CMS, $5 \mathrm{~g}$ AA (neutralization degree of $100 \%$ by $10 \mathrm{wt} . \% \mathrm{NaOH}$ solution), $1 \mathrm{~g}$ AM, $0.25 \mathrm{~g}$ APS, and 0.25 g MBA.

\section{Heavy metal adsorption experiments}

\section{Effect of coexisting $\mathrm{Na}^{+}$ions on adsorption}

Figure 3 shows the adsorption capacities of the high crosslinked CMS-g-poly (AA-co-AM) resin (HCAA) in four 

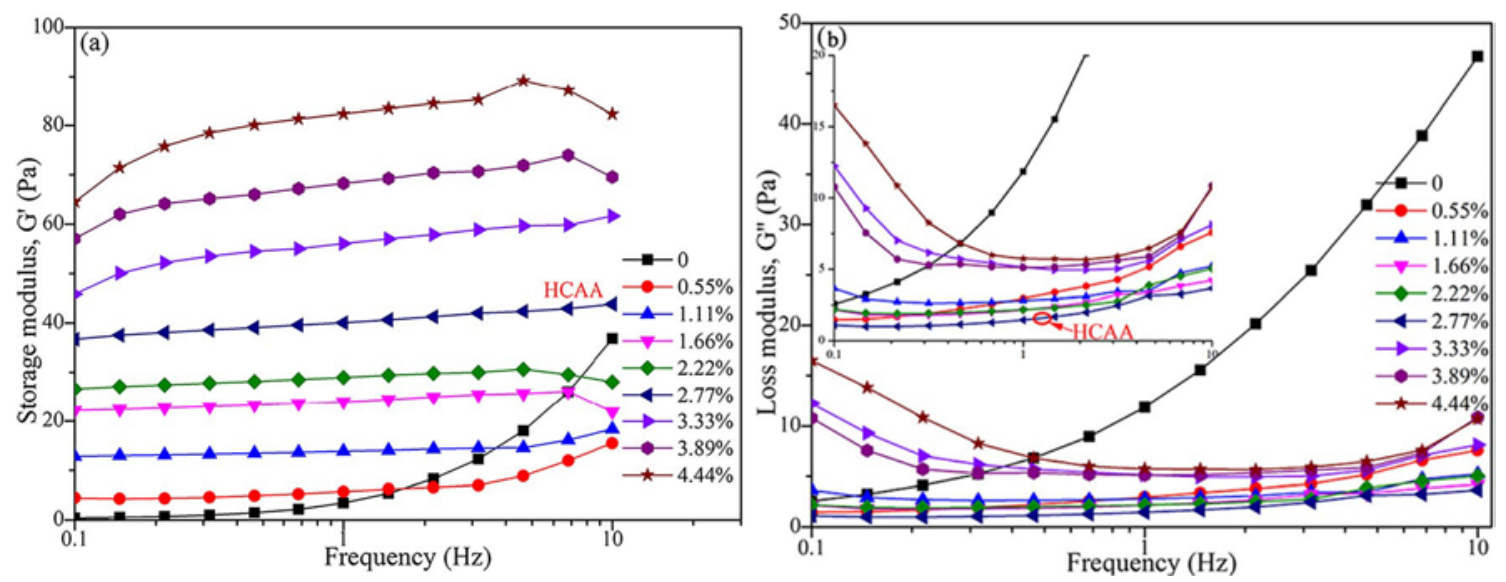

Fig. 2 Effect of MBA contents on storage modulus (a) and loss modulus (b) of CMS- $g$-poly (AA-co-AM 


\begin{tabular}{|c|c|c|c|c|c|}
\hline & Polymerization system & Initiator & $\begin{array}{l}\text { Content of MBA } \\
\text { (wt.\%) }\end{array}$ & $\begin{array}{l}\text { Water absorbency } \\
\text { (g/g) }\end{array}$ & Reference \\
\hline 1 & Salep-g-poly (AA) & APS & 0.8 & 3050 & Pourjavadi et al. (2008) \\
\hline 2 & Chitosan- $g$-poly (AA) & ACS & 1.64 & 704 & Ge et al. (2006) \\
\hline 3 & CMC-g-poly (AA) & Plasma & 0.3 & 1330 & Yu et al. (2014) \\
\hline 4 & Cellulose-g-poly (AA-co-AM) & Microwave & 0.25 & 1388 & Shu et al.(2011) \\
\hline 5 & Chitosan- $g$-poly (AA-co-AM) & KPS & 2.0 & 220 & Mahdavinia et al.(2004) \\
\hline 6 & Silk sericin- $g$-poly (AA-co-AM) & KPS & 0.068 & 2150 & $\mathrm{Hu}(2011)$ \\
\hline 7 & PACS-g-poly (AA-co-AM) & APS & 0.4 & 615 & Kenawy et al.(2019) \\
\hline 8 & $\beta$-Cyclodextric- $g$-poly (AA-co-AM) & KPS & 0.04 & 1544 & Huang et al.(2013) \\
\hline 9 & QAC-g-poly (AA-co-AM) & KPS & 0.2 & 360 & He et al. (2017) \\
\hline 10 & Wheat straw-g-poly(AA-co-AM/DMDAAC) & KPS & 0.2 & 133 & Ma et al. (2011) \\
\hline 11 & Sodium alginate- $g$-poly (AA-co-HEMA)/montmorillonite & KPS & 0.06 & 752 & Fang et al. (2019) \\
\hline 12 & CMS- $g$-poly (AA-co-AM) & APS & 2.77 & 53.64 & This work \\
\hline
\end{tabular}

Note: $C M C$, carboxymethyl cellulose; $Q A C$, quaternary ammonium chitosan; DMDAAC, dimethyl diallyl ammonium chloride; HEMA, 2-hydroxyehyl methacrylate; $A P S$, ammonium persulfate; $A C S$, ammonium cerous sulfate; $K P S$, potassium persulfate

heavy metal solutions with different initial $\mathrm{Na}^{+}$concentra- tions. As the $\mathrm{Na}^{+}$concentration increased, the adsorption ca- pacity of HCAA resin maintained a smooth state when the $\mathrm{Na}^{+}$concentration was lower than $0.01 \mathrm{~mol} / \mathrm{L}$ and decreased thereafter. These results were observed because $\mathrm{Na}^{+}$concen- tration significantly affects the dissociation of the adsorption functional groups -COONa in the polymer chains. When the resin are immersed in heavy metal solution, the macromolec- ular chains of the polymer are extended, accompanied with - COONa ionizing into $-\mathrm{COO}^{-}$and $\mathrm{Na}^{+}$. Finally, the increase of $\mathrm{Na}^{+}$ concentration brings an increase of the ionization

resistance to shield the active sites of $-\mathrm{COO}^{-}$. In addition, a large amount of $\mathrm{Na}^{+}$also causes the increase of the cationic density and decreases the contacting probability of the disso- ciative heavy metal ions to the functional adsorption group of

$-\mathrm{COO}^{-}$. Thus, under too high $\mathrm{Na}^{+}$concentration, the heavy

metal adsorption capacity of HCAA is declined significantly.

\section{Effect of heavy metal types on adsorption}

The maximum heavy metal adsorption capacities of HCAA resin are also obtained from Fig. 3. It could be seen that under

Fig. 3 Effect of $\mathrm{Na}^{+}$

concentration on heavy metal adsorption capacity of HCAA resin. $\left(C_{0}, 200 \mathrm{mg} / \mathrm{L} ; \mathrm{V}, 50 \mathrm{~mL}\right.$; $\left.m, 0.05 \mathrm{~g} ; \mathrm{T}, 25^{\circ} \mathrm{C}\right)$

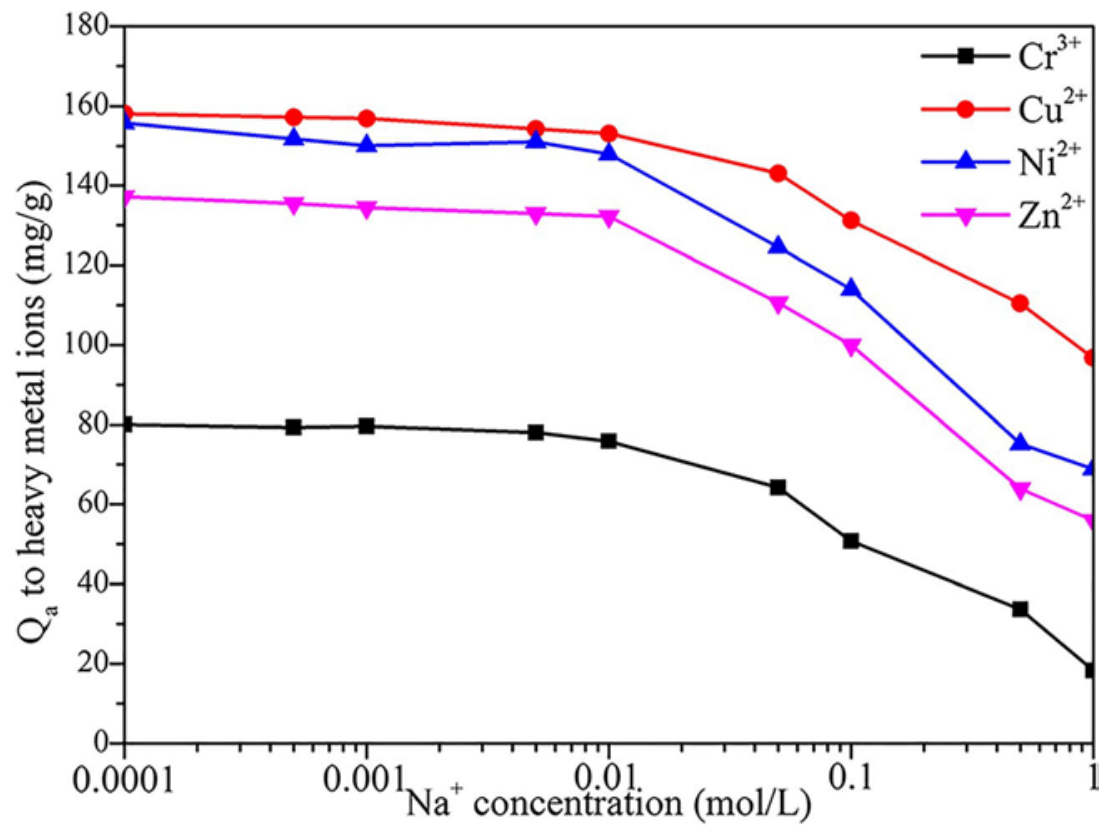


the same experimental conditions of the initial $200 \mathrm{mg} / \mathrm{L}$ con- centration, the adsorption capacities of HCAA resin to $\mathrm{Cr}^{3+}$, $\mathrm{Cu}^{2+}, \mathrm{Ni}^{2+}$, and $\mathrm{Zn}^{2+}$ were $80.08,158.07,155.71$, and

$137.15 \mathrm{mg} / \mathrm{g}$, respectively, which exhibited the following or- der: $\mathrm{Cu}^{2+}>\mathrm{Ni}^{2+}>\mathrm{Zn}^{2+}>\mathrm{Cr}^{3+}$. For comparison, chitosan/ acidactivated montmorillonite/acrylic acid composite hydro- gel presented $42.38 \mathrm{mg} / \mathrm{g}$ capacity for $\mathrm{Ni}^{2+}$ (Vieira et al. 2018). The adsorption capacity of poly (AA-co-AM) was

$39.5 \mathrm{mg} / \mathrm{g}$ for $\mathrm{Cu}^{2+}$ and $37 \mathrm{mg} / \mathrm{g}$ for $\mathrm{Ni}^{2+}$ (Ali et al. 2018). The maximum $\mathrm{Cu}^{2+}$ and $\mathrm{Ni}^{2+}$ ion uptake by sodium alginate- g-poly (AA-co-AM) are 76.35 and $67.35 \mathrm{mg} / \mathrm{g}$ (Tally and Atassi 2016). The adsorption capacity to modified cellulose hydrogel by $\mathrm{AA}$ and $\mathrm{AM}$ of $\mathrm{Cu}^{2+}$ was $157.51 \mathrm{mg} / \mathrm{g}$ (Zhao et al. 2019). Therefore, there are potential trends that the ad- sorbent with high adsorption performance can be obtained. Specifically, from the coordination chemistry theory, the com- plexes for the trivalent positive ions, such as $\mathrm{Cr}^{3+}$, with $-\mathrm{COO}^{-}$, must undergo the $d^{2} s p^{3}$ atomic hybridization to form a regular octahedron and attain a stable structure, where for bivalent positive ions it must undergo the $d s p^{2}$ atomic hybrid- ization to form the plane quadrangle and attain a stable struc- ture. Interestingly, these interacting models are similar with the titration analysis of the ethylene diamine tetraacetic acid (EDTA) on the basis of the complex reaction.

Furthermore, these diversities on the heavy metal adsorp- tion capacities are consistent with the values of complexation stability constant $K$ of the chelating reaction for $-\mathrm{COO}^{-}$func- tional groups to metal ions, and its calculation methods are expressed as Eq. (2):

from the innovation of the preparation methods.

The adsorption essences of HCAA to the heavy metal ions could be explained by HSAB theory (the hard, soft acids, and bases theory), which are attributed to the combination be- tween the functional $-\mathrm{COO}^{-}$and the free heavy metal ions in the solution (Ni et al. 2018). Thus, on another aspect, the heavy metal ions can be divided into "the Lewis acid" which has the ability to obtain single electron pairs owing to its

vacant d atom orbit, where the HCAA resin can be regarded as "the Lewis alkali" for donation of long pair electrons on the $-\mathrm{COO}^{-}$groups.

During the coordination reaction, the electropositive heavy metal ions and the electronegative $-\mathrm{COO}^{-}$would be com- bined to form stable complexes via the electrostatic attraction and the coordination bond action (Jiang et al. 2019; Singh and Singhal 2012). More specifically, the coordination bond ac- tion is formed by sharing the long pair electrons of the active oxygen with a negative point in $-\mathrm{COO}^{-}$to positive heavy metal ions. As shown in Fig. 4, the functional groups contain- ing HCAA resin to adsorb heavy metals is only $-\mathrm{COO}^{-}$, ex- where $Z$ and $r$ are the electric charges and radius of the metal ions, respectively; $X_{ \pm}$ is the ration of the sum to the difference of the electronegativity between the atomic ad- sorption sites and the adsorbed heavy metal ions; and $A, B$, and $C$ are the constants determined by the ligands com- posed both of the adsorbent and heavy metals (Chen 1977; Chen 1980).

Equation (2) reveals that the chelation of the ligand ex- changing adsorbents with the dissolved metals are not only jointly associated with the valence and steric hindrance of the adsorbed ion radius $\left(\mathrm{Cr}^{3+}, 0.0615 \mathrm{~nm}<\mathrm{Ni}^{2+}, 0.069 \mathrm{~nm}\right.$ $<\mathrm{Cu}^{2+}, 0.073 \mathrm{~nm}<\mathrm{Zn}^{2+}, 0.074 \mathrm{~nm}$ ) but also decided by the

affinity difference between metal ions and coordination ions of the adsorbent (Volkov et al. 1997). From Table 2, the order of $\lg K$ is $\mathrm{Cr}^{3+}(6.897)>\mathrm{Cu}^{2+}(3.60)>\mathrm{Ni}^{2+}(3.49)>\mathrm{Zn}^{2+}(3.20)>>\mathrm{Na}^{+}(0.99)$, which is consistent with the above phenomena for the bivalent ion adsorption (Lawson et al. 1984). And compared with other bivalent ions, the inconcluding $-\mathrm{CONH}_{2}$ and $-\mathrm{OH}$, which has been confirmed from gruity in the lowest adsorption capacity for $\mathrm{Cr}$ is by virtue our previous study listed in literature (Zhang et al. 2019).of the difference of the valence and the spatial combination 


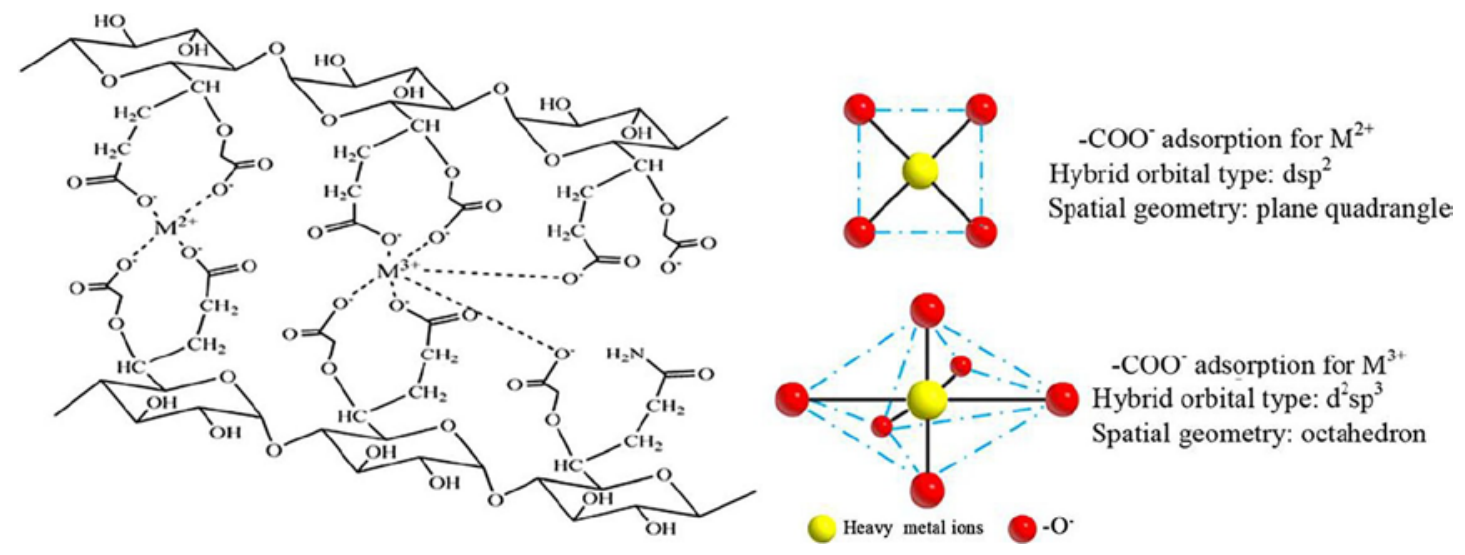


Table 2 Calculation of the complexation stability constant $K$ to HCAA adsorbent

\begin{tabular}{lllrlll}
\hline Metals & \multicolumn{7}{l}{ Values } & \multicolumn{1}{c}{} \\
\cline { 2 - 7 } & $r(\mathrm{~nm})$ & Electronegativity & \multicolumn{1}{c}{$Z^{2} / r$} & $X_{ \pm}$ & $\lg K_{\mathrm{a}}$ & $\lg K_{\mathrm{b}}$ \\
\hline $\mathrm{Cr}^{3+}$ & 0.0615 & 1.66 & 146.34 & 2.86 & 6.89 & 23.4 \\
$\mathrm{Cu}^{2+}$ & 0.069 & 1.9 & 57.97 & 3.46 & 3.60 & 18.80 \\
$\mathrm{Ni}^{2+}$ & 0.073 & 1.91 & 54.79 & 3.49 & 3.49 & 18.60 \\
$\mathrm{Zn}^{2+}$ & 0.074 & 1.65 & 54.05 & 2.84 & 3.20 & 16.50 \\
$\mathrm{Na}^{+}$ & 0.102 & 0.93 & 9.80 & 1.74 & 0.99 & 1.66 \\
\hline
\end{tabular}

Note: $A=0.04, B=0.4, C=-0.1$ (referring to the $\lg K$ calculation of malonic acid $\left(\mathrm{CH}_{2}(\mathrm{COOH})_{2}\right)$. $\lg K_{\mathrm{a}}$ of HCAA resin and $\lg K_{\mathrm{b}}$ of EDTA
Table 3 Element content analysis of the surface of HCAA resin before and after adsorbing heavy metal ions by $\operatorname{EDS}\left(C_{0}, 200 \mathrm{mg} / \mathrm{L} ; \mathrm{V}, 100 \mathrm{~mL}\right.$; $\left.m, 0.10 \mathrm{~g} ; T, 25^{\circ} \mathrm{C}\right)$

\begin{tabular}{|c|c|c|c|c|c|c|c|c|}
\hline & \multicolumn{8}{|c|}{ Element weight percentages (wt.\%) } \\
\hline & $\mathrm{C}$ & $\mathrm{N}$ & $\mathrm{O}$ & $\mathrm{Na}$ & $\mathrm{Cr}$ & $\mathrm{Cu}$ & $\mathrm{Ni}$ & $\mathrm{Zn}$ \\
\hline HCAA & 41.11 & 2.44 & 37.16 & 19.29 & - & - & - & - \\
\hline HCAA-Cr & 44.03 & 4.16 & 39.87 & 0.01 & 11.93 & - & - & - \\
\hline HCAA-Cu & 46.76 & 4.87 & 28.67 & 0 & - & 19.7 & - & - \\
\hline HCAA-Ni & 43.67 & 4.69 & 43.9 & 0.19 & - & - & 7.55 & - \\
\hline tocAfferent 1 & 45,35 & ilit & rese & ively & - & - & - & 19.18 \\
\hline
\end{tabular}

difference, leading to the lower adsorption amounts to $\mathrm{Cr}^{3+}$. Finally, in the adsorption experiments, the $-\mathrm{COO}^{-}$groups of HCAA resin have different capacities for different metal ions. Meanwhile, it also reveals the selectivity that the resin can only adsorb heavy metal ions preferentially but not react with $\mathrm{Na}^{+}$.

\section{Effect of time-dependent behaviors on adsorption}

Figure 5 shows the concentration curves of heavy metal ions and $\mathrm{Na}^{+}$in the residual solution during HCAA resin adsorbing heavy metal ions. By immersing HCAA resin into the heavy metal solution, the concentration of heavy metal ions decreased with the increase of the immersing time, accompanied with the increase of $\mathrm{Na}^{+}$concentration inversely, and finally leveled with the curves of the $\mathrm{Na}^{+}$concentration, respectively. Furthermore, these two curves were centrally symmetric in every heavy metal solutions, which affirmed that the heavy

metal adsorption process of the resin was in accordance with ion exchange process (Zou et al. 2019). This conclusion could also be confirmed by the EDS analysis of the element change to HCAA resin before and after adsorbing heavy metal ions, and the results are shown in Table 3. The signif-icant diminution of Na element contents from $19.29 \mathrm{wt}$ \% to hardly any Na detected on the resin surface, and the en- hancement of heavy metal element contents, including

11.93 wt.\% for $\mathrm{Cr}, 19.70 \mathrm{wt}$ \% for $\mathrm{Cu}, 7.55 \mathrm{wt} . \%$ for Ni, and $19.18 \mathrm{wt}$ \% for Zn, respectively, strongly demonstrated the ion exchange process of HCAA resin in the heavy metal aqueous solutions. The ionized $\mathrm{Na}^{+}$are released from the polymer chains and then migrated into the external solution, accompanied with the process that the unoccupied $-\mathrm{COO}^{-}$are combined with the free heavy metal ions to form the stable chelation complexes (Holyavka et al. 2017). So, based on the ion exchange process, the phenomena, including the decrease of the heavy metal concentration and the increase of the $\mathrm{Na}^{+}$, were detected synchronously in the external solution.

Fig. 5 Effect of timedependence on heavy metal and $\mathrm{Na}^{+}$ concentration in aqueous solution of the process of HCAA resin adsorbing heavy metal ions $\left(C_{0}\right.$, $200 \mathrm{mg} / \mathrm{L} ; \mathrm{V}, 100 \mathrm{~mL} ; \mathrm{m}, 0.10 \mathrm{~g}$; $\left.T, 25^{\circ} \mathrm{C}\right)$

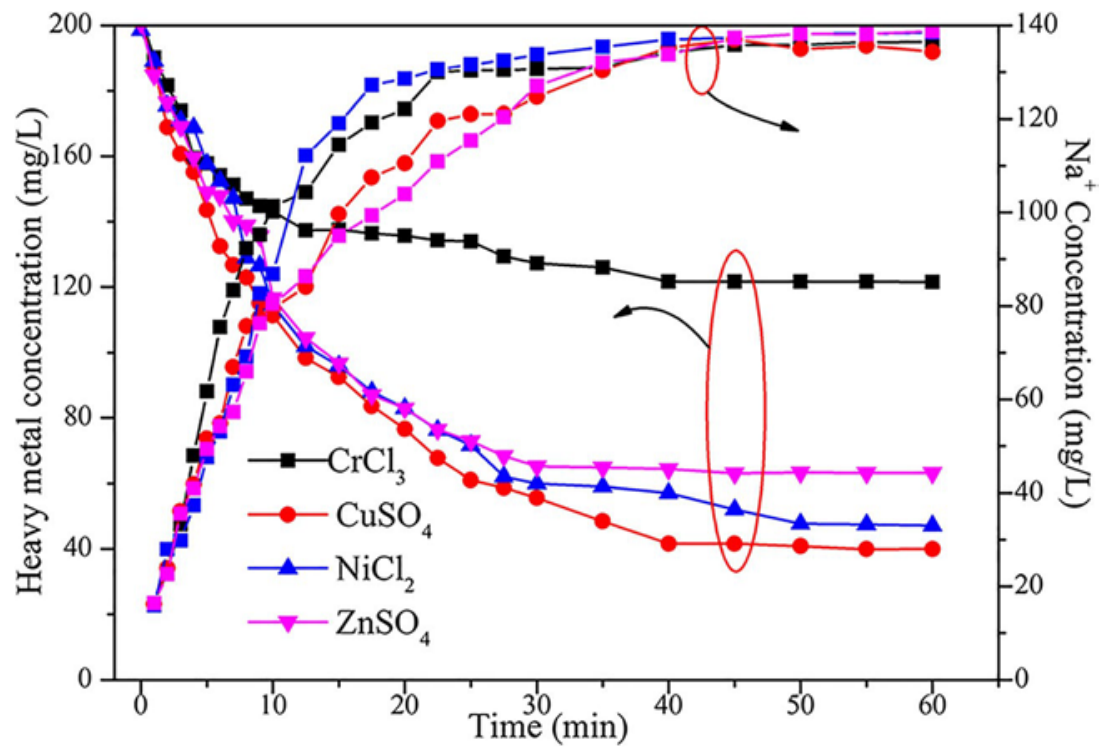


Fig. 6 The FT-IR spectra of the HCAA resin (a) and HCAA resin after adsorption for $\mathrm{Cr}^{3+}(\mathrm{b}), \mathrm{Cu}^{2+}$ (c), $\mathrm{Ni}^{2+}(\mathrm{d})$, and $\mathrm{Zn}^{2+}(\mathrm{e})$

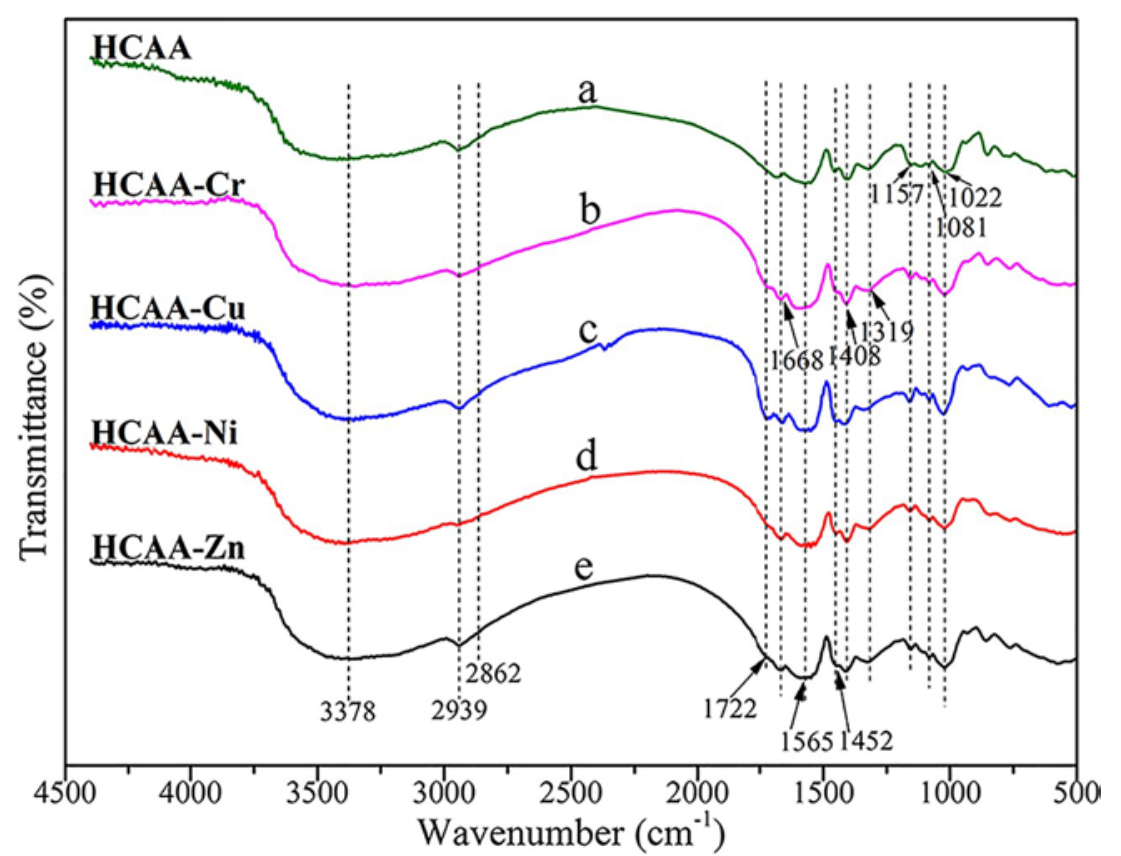

\section{FTIR spectra analysis}

The FTIR spectra of HCAA resin before and after adsorbing heavy metal ions are shown in Fig. 6. The strong overlapping peaks at 1022, 1081, and $1157 \mathrm{~cm}^{-1}$ for $\mathrm{C}-\mathrm{O}-\mathrm{C}$ groups and the strong and wide peaks at $3378 \mathrm{~cm}^{-1}$ for the $-\mathrm{OH}$ groups are the characteristic bonds of CMS (Huang et al. 2012). The strong overlapping peaks at $1668 \mathrm{~cm}^{-1}$ can be attributed to $-\mathrm{C}=\mathrm{O}$ stretching vibration peaks because of $p-\pi$ conjugation between the nitrogen atoms and carbonyl groups, the sharp adsorption peaks at $1408 \mathrm{~cm}^{-1}$ is the $\mathrm{C}-\mathrm{N}$ spectral bands, and the weak adsorption peaks at $1319 \mathrm{~cm}^{-1}$ is the coupled adsorption peaks between the $\mathrm{N}-\mathrm{H}$ and $\mathrm{C}-\mathrm{N}$ groups, which are all the characteristic bonds of $-\mathrm{CONH}_{2}$ for acrylamide monomer. The symmetric stretching vibration peak at $1452 \mathrm{~cm}^{-1}$,

the asymmetric stretching vibration peak at $1565 \mathrm{~cm}^{-1}$, and the bending vibration adsorption peak at $1722 \mathrm{~cm}^{-1}$ are main- ly ascribed to the -COONa groups (Kolya et al. 2014). The methylene $-\mathrm{CH}_{2}-$ adsorption peaks from the acrylamide and acrylic acids are also observed at 2862 and $2939 \mathrm{~cm}^{-1}$, respectively. Based on these results, it is proved that the HCAA resin is successfully obtained under the radical-initiated polymerization reaction by all starting materials, including CMS, AA, and AM. Furthermore, the strength of $-\mathrm{COO}^{-}$adsorption peaks are significantly increased after the HCAA resin adsorbed heavy metal ions, which are mainly due to the extension of the polymer chains and the formation of the complexes.

\section{Morphology analysis}

The macromorphologies of the HCAA resin before and after adsorbing heavy metal ions from the aqueous solution are shown in Fig. 7. It can be obviously seen that after adsorbing heavy metal ions, the particles are all with saturated colors corresponding to the adsorbed ions and have no water absor- bency at all, which reveal the excellent heavy metal adsorption capacities of the HCAA resin. Furthermore, SEM was also used to observe the structure changes in the adsorption process, and the results are shown in Fig. 8. The surface of the dried HCAA resin is distributed with some irregular cracks and densified structure as the result of the sharp contraction when drying. However, from Fig. 8c, d of the surface and Fig. 8e, $f$ of the cross-section observation of the resin after 

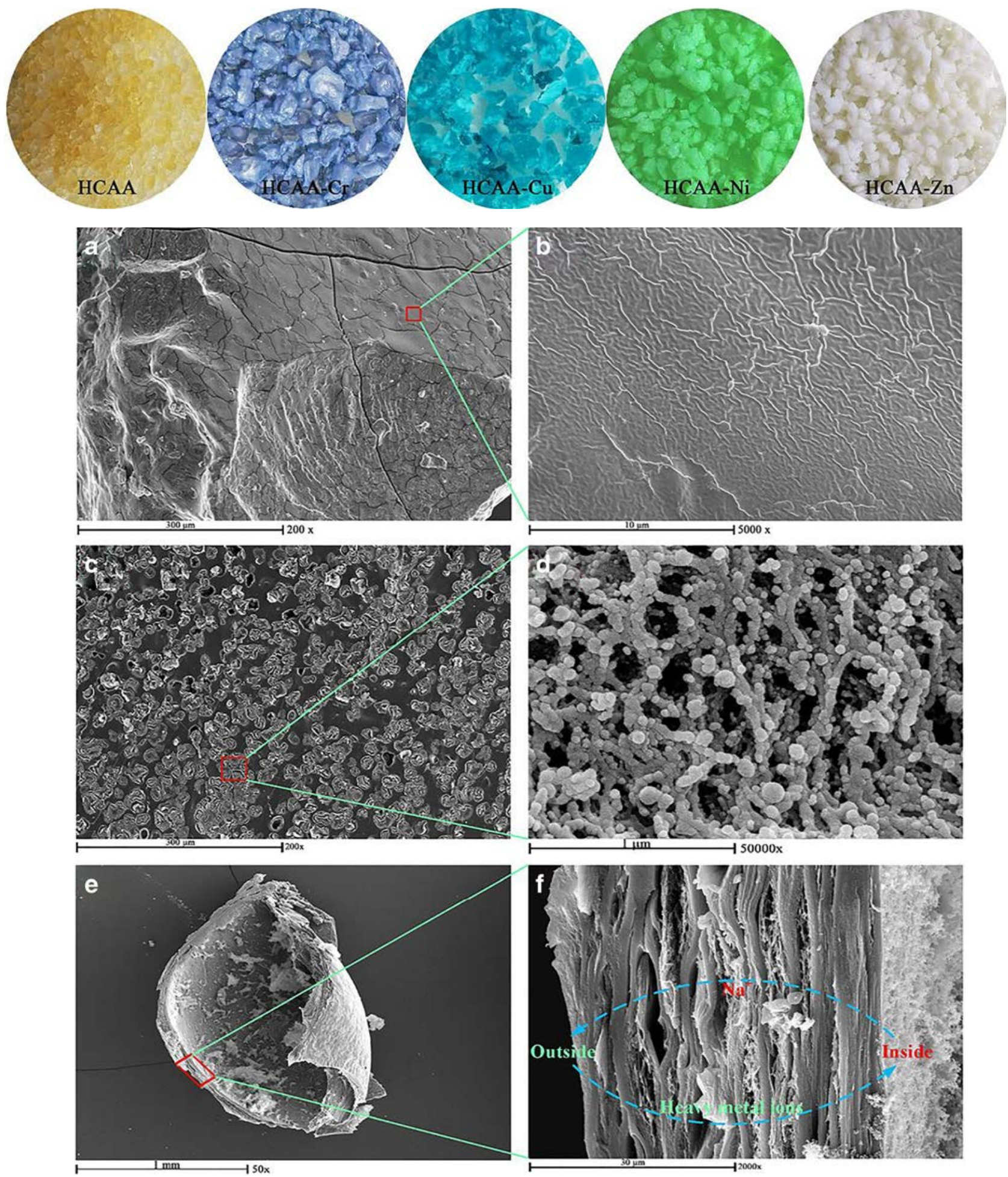

Fig. 8 SEM micrographs of a, b the surface of HCAA resin, c, $d$ the surface of HCAA resin after adsorbing heavy metal ions, and e, f the cross section of HCAA resin after adsorbing heavy metal ions

adsorbing heavy metal ions, the phenomenon of compact lay- er disappeared and the high magnification SEM images demonstrate that after being immersed in the heavy metal solution, the nanometer molecular chains of the HCAA resin are dilat- ed. And its emerging porous structures provide a series of transporting channels for the interexchanging process between $\mathrm{Na}^{+}$and heavy metal ions. These observations are related to the advantage of graft copolymerization to gain the polymer with ultrahigh molecular weight (UHWP) by simple mate- rials. Introducing the free radicals and junctions by adding the initiator and the crosslinker, the networks could be formed, which provided the products with the nanohole structures and the superior adsorption property.

\section{Adsorption kinetics}


Adsorption equilibrium for the heavy metal ion adsorption of HCAA resin in the solution was analyzed using the WeberMorris and Fickian diffusion models, where the former was used to investigate the heavy metal adsorption process and the latter was used to observe the $\mathrm{Na}^{+}$diffusing process during the whole ion exchanging process, respectively (Zhao et al. 2019). These two kinetic models are expressed as Eqs. (3) and (4):

$Q_{\text {at }}{ }^{1 / 4} k_{\mathrm{a}} t^{0: 5} \mathrm{p} C_{\mathrm{a}}$

ð3Р

$Q_{\mathrm{dt}} 1 / 4 k_{\mathrm{d}} t \mathrm{p} C_{\mathrm{d}}$ 
where $Q_{\text {at }}$ and $Q_{\mathrm{dt}}$ are the adsorption capacity of heavy metal ions and the diffusion capacity of $\mathrm{Na}^{+}(\mathrm{mg} / \mathrm{g}), k_{\mathrm{a}}$ and $k_{\mathrm{d}}$ are the intraparticle diffusion rate constants $\left(\mathrm{mg} /\left(\mathrm{g} / \mathrm{min}^{0.5}\right), \mathrm{mg} /\right.$

(g/min)), and $C_{\mathrm{a}}$ and $C_{\mathrm{d}}$ are the intercepts which reflect the boundary layer effects, respectively.

The adsorption curves shown in Fig. 5 are linearly fitted by Eqs. (3) and (4) and shown in Fig. 9. Moderately good regressions are obtained from these two models by judgment of $R^{2}$ and sum of squared residual (SSR), and the fitted kinetic parameters are listed in Table 4. During the ion exchange pro- cess of HCAA resin in four different heavy metal solutions, the value of $k_{\mathrm{a}}$ and $k_{\mathrm{d}}$ decreased and the value of $C_{\mathrm{a}}$ and $C_{\mathrm{d}}$ increased contrarily as the reaction proceeding, which re- vealed the increase of the diffusion and migration resistances to the freely distributed soluble ions, both for heavy metal ions and the ionized $\mathrm{Na}^{+}$.

Immersing HCAA resin into the heavy metal solution, the initial adsorption process was mainly dominated by the sur- face granular layer in the first 10 min because of the dense structure of the dried resin and the osmotic pressure difference that occurred in the system. Under the hydrophilic expansibility of - $\mathrm{COONa}$ and $-\mathrm{OH}$ groups surrounded by water molecules, the external polymer chains begin to ex- tend preferentially, along with more and more water trans- ferring into the reticular structure of the resin. Meanwhile, the dissociation of $-\mathrm{COONa}$ into $-\mathrm{COO}^{-}$and $\mathrm{Na}^{+}$created a driving force of the ion concentration difference to drive heavy metal ions migrate into the particles, which also drove the ionized $\mathrm{Na}^{+}$migrate outside of the particles. On the other hand, owing to the sharp difference of complexing selectiv- ity of $-\mathrm{COO}^{-}$to heavy metal ions and $\mathrm{Na}^{+}$: heavy metal $>\mathrm{Na}^{+}$, the complex action of $-\mathrm{COO}^{-}$on the grafted chains of resin with bivalent or trivalent metal cation caused the de- crease of heavy metal concentration and the increase of $\mathrm{Na}^{+}$concentration, which all brought a huge shrink of the crosslinked network structures.

Specifically, during the emission of $\mathrm{Na}^{+}$and the migration of heavy metal ions, the former is driven with the os- motic pressure difference created by $\mathrm{Na}^{+}$concentration, where its diffusion flux is positively correlated with the dif- fusion time; however, the latter do not solely rely on the osmotic pressure as a consequence of the ionic groups but also to the electrostatic attraction between the anionic - $\mathrm{COO}^{-}$groups and the cationic heavy metal ions. Next, when
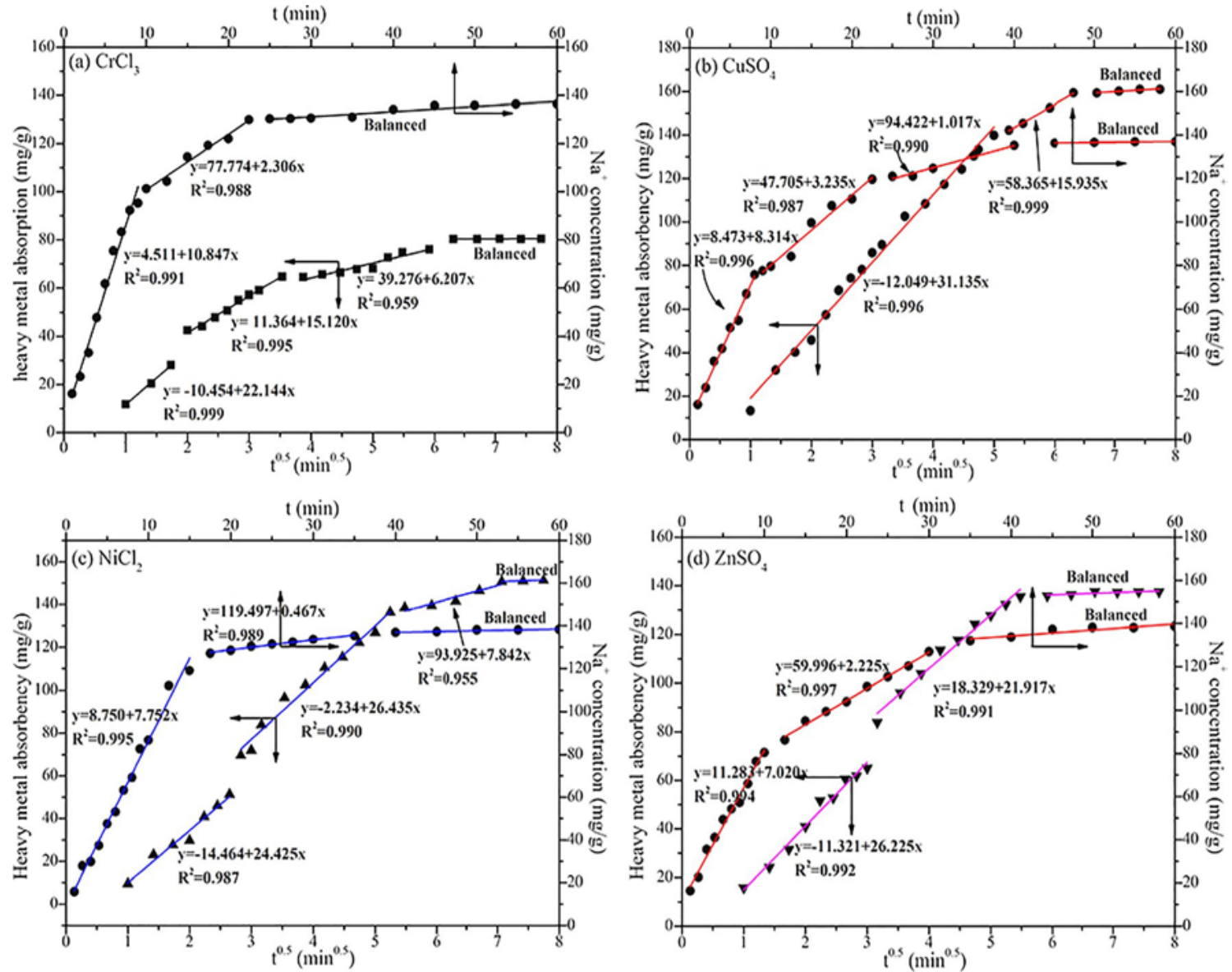

Fig. 9 Adsorption kinetic fitting to HCAA resin of heavy metal being adsorbed and $\mathrm{Na}^{+}$diffusing processes at different heavy metal solutions $\left(C_{0}\right.$, $\left.200 \mathrm{mg} / \mathrm{L} ; V, 100 \mathrm{~mL} ; \mathrm{m}, 0.10 \mathrm{~g} ; \mathrm{T}, 25^{\circ} \mathrm{C}\right)$ 
Table 4 Adsorption kinetic parameters to HCAA resin of heavy metal adsorption and $\mathrm{Na}^{+}$diffusion processes at different heavy metal solutions $\left(C_{0}\right.$, $\left.200 \mathrm{mg} / \mathrm{L} ; \mathrm{V}, 100 \mathrm{~mL} ; \mathrm{m}, 0.10 \mathrm{~g} ; \mathrm{T}, 25^{\circ} \mathrm{C}\right)$

\begin{tabular}{|c|c|c|c|c|c|c|c|c|c|c|}
\hline \multirow[t]{2}{*}{ Solution } & \multirow[t]{2}{*}{ Ions } & \multicolumn{4}{|c|}{ Adsorption for heavy metal ions } & \multirow[t]{2}{*}{ Ions } & \multicolumn{4}{|c|}{ Diffusion of $\mathrm{Na}^{+}$} \\
\hline & & $k_{\mathrm{a}}$ & $C_{\mathrm{a}}$ & $R^{2}$ & SSR & & $k_{\mathrm{d}}$ & $C_{\mathrm{d}}$ & $R^{2}$ & SSR \\
\hline \multirow[t]{3}{*}{$\mathrm{CrCl}_{3}$} & \multirow[t]{3}{*}{$\mathrm{Cr}^{3+}$} & 22.144 & -10.454 & 0.999 & 0.266 & \multirow[t]{3}{*}{$\mathrm{Na}^{+}$} & 10.847 & 4.511 & 0.991 & 75.799 \\
\hline & & 15.12 & 11.364 & 0.995 & 3.541 & & 2.306 & 77.774 & 0.988 & 14.402 \\
\hline & & $\begin{array}{c}6.207 \\
\text { Balanced }\end{array}$ & 39.276 & 0.959 & 10.933 & & Balanced & & & \\
\hline \multirow[t]{3}{*}{$\mathrm{CuSO}_{4}$} & \multirow[t]{3}{*}{$\mathrm{Cu}^{2+}$} & 31.135 & -12.049 & 0.996 & 137.85 & \multirow[t]{3}{*}{$\mathrm{Na}^{+}$} & 8.314 & 8.473 & 0.996 & 23.964 \\
\hline & & 15.935 & 58.365 & 0.999 & 0.247 & & 3.235 & 47.705 & 0.987 & 42.452 \\
\hline & & Balanced & & & & & Balanced & & & \\
\hline \multirow[t]{3}{*}{$\mathrm{NiCl}_{2}$} & \multirow[t]{3}{*}{$\mathrm{Ni}^{2+}$} & 24.425 & -14.464 & 0.987 & 32.812 & \multirow[t]{3}{*}{$\mathrm{Na}^{+}$} & 7.752 & 8.75 & 0.995 & 126.955 \\
\hline & & 26.435 & -2.234 & 0.990 & 89.384 & & 0.467 & 119.497 & 0.989 & 1.044 \\
\hline & & $\begin{array}{c}7.842 \\
\text { Balanced }\end{array}$ & 93.925 & 0.955 & 9.392 & & Balanced & & & \\
\hline \multirow[t]{3}{*}{$\mathrm{ZnSO}_{4}$} & \multirow[t]{3}{*}{$\mathrm{Zn}^{2+}$} & 26.225 & -11.321 & 0.992 & 40.468 & \multirow[t]{3}{*}{$\mathrm{Na}^{+}$} & 7.02 & 11.283 & 0.994 & 49.451 \\
\hline & & 21.917 & 18.329 & 0.991 & 41.901 & & 2.225 & 59.996 & 0.997 & 6.884 \\
\hline & & Balanced & & & & & Balanced & & & \\
\hline
\end{tabular}

the surface layers reached the adsorption saturation, the ad- sorption of HCAA resin is converted into the internal diffu- sion and chelation of heavy metal ions. Transferring from external to internal particles, the heavy metal ions must pass through the nanoholes to reach the innermost layer of the resin, where the greater resistance for the adsorption process- es is exhibited (Naseem et al. 2019). The decrease of the osmotic difference and the increase of mass transfer resis- tance all contribute to an opposite relationship between the $K$ and $C$ values in the next stage ( $\mathrm{Li}$ et al. 2019). Finally, the adsorption equilibriums are obtained when all $\mathrm{Na}^{+}$were dispersed into aqueous solution and all active func- tional sites were occupied by the chelated heavy metal ions.
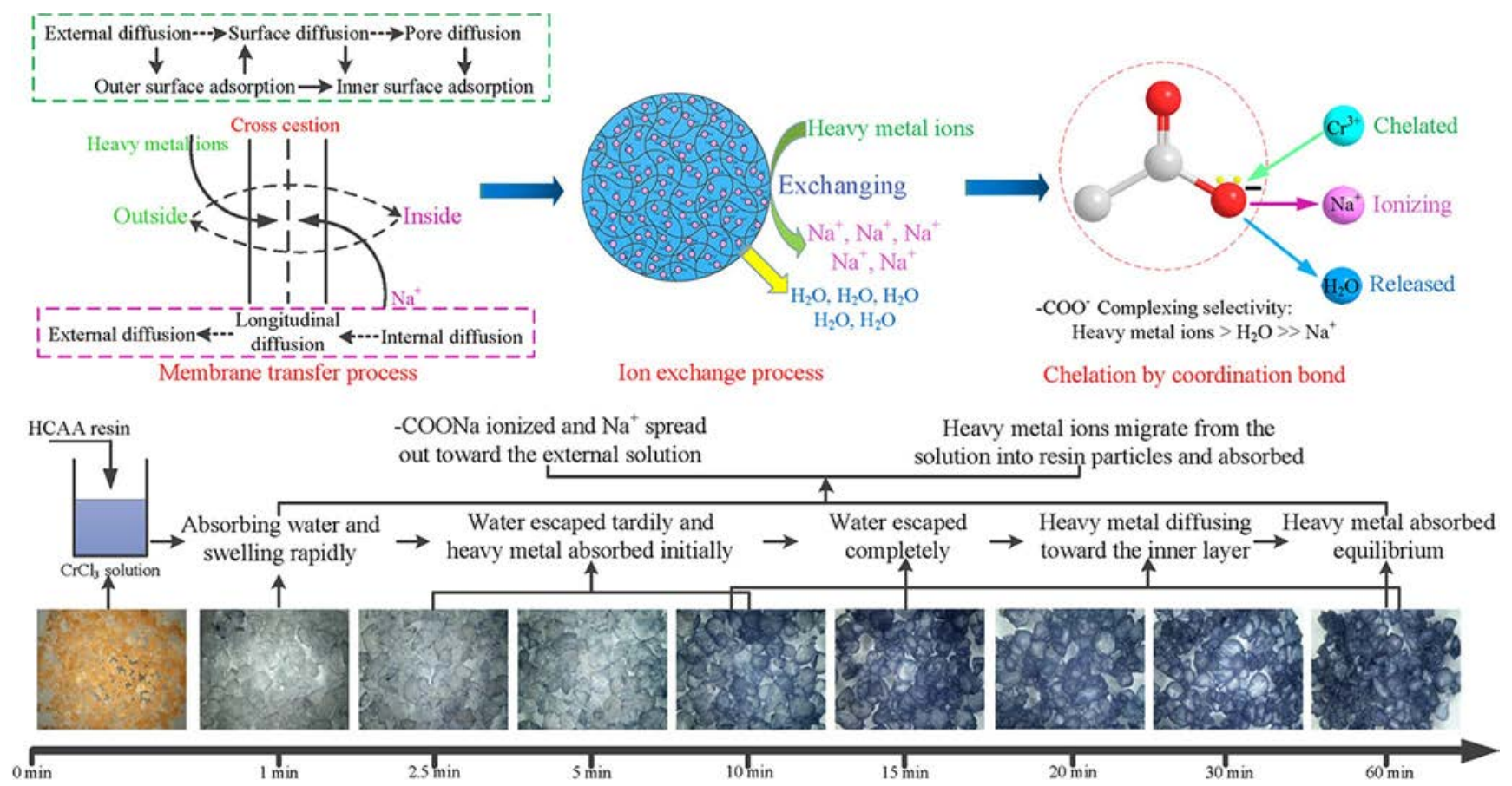

Fig. 10 Schematic illustration of the adsorption process and interaction between HCAA resin and the heavy metal solution 


\section{Adsorption mechanism}

To better explain the adsorption and material transfer pro- cess of HCAA resin, apparent morphology in each phase of the adsorption process was observed and shown in Fig.

10. Essentially, the adsorption process can be considered the exchange of two phases, for which one is the adsorp- tion of pollutants and the other is the seceding process of containing free ions in the adsorbent. In the prior stage, the heavy metal solution can be regarded as the strong electrolyte solution, where the dried HCAA resin is clas- sified as the polyelectrolyte substances. So putting HCAA resin into the heavy metal solution, and under the action of the water osmotic pressure, the water molecules get into the particles at once, which lead the resin to swell rapidly in the first time. After immersing the polymer chains being in water, instantaneous ionization of

-COONa followed as well as the firm combination of

$-\mathrm{COO}^{-}$with water molecules. Over the next $10 \mathrm{~min}$, wa- ter molecules escaped tardily and heavy metal ions are adsorbed initially on the outer surface, accompanied with the constant migration of the ionized $\mathrm{Na}^{+}$from the inside to the outside of the particles. Especially at $15 \mathrm{~min}$, the fixed water molecules escaped completely from the resin, continuing with the dynamic exchange of heavy metal adsorption and the $\mathrm{Na}^{+}$diffusion. Meanwhile, the cross section of the swollen resin could be considered the ion exchange channels, where exchange process between the easily releasing ions and the strongly combined ions oc- curred. Thus, after adsorption saturation reached the sur- face layer, heavy metal ions transfer ulteriorly toward the inner layer through pore diffusion. In the end, the adsorp- tion equilibrium has been obtained after the ionized $\mathrm{Na}^{+}$diffused into the aqueous solution and the adsorbing active sites are all being occupied under the synergistic interaction of the chelation with the heavy metal ions, which also indicate the completion of the ion exchange process between heavy metal and $\mathrm{Na}^{+}$ions. In addition, from these observations and the dynamic change of the ion concentration in the solution (including $\mathrm{Na}^{+}$and heavy metal ions), the phenomenon has been ignored in previous researches that by comparing with other ions, water mol- ecules are at the highest priority to get into the inside of the expansive adsorbent, which also accelerate the migra- tion rate for all cations. And the conclusion can be drawn from this experiment that for the expansive adsorbents, the selectivity sequence of the functional -COONa groups is as follows: heavy metal ions $>\mathrm{H}_{2} \mathrm{O}>>$ $\mathrm{Na}^{+}$and the adsorption process in the solution are divided into the outer surface and inner layer adsorption.

\section{Conclusions}

High crosslinked sodium carboxyl methylstarch-g-poly (AA- co-AM) resin (HCAA) was prepared by graft copolymerization to adsorb heavy metal pollutants from aqueous solution. Experimental results indicated that increasing the crosslinker contents in graft copolymerization reaction can make the syn- thesized polymer insoluble and create nano-three-dimensional network structures. The sample analysis and kinetic model fitting results confirmed that the heavy metal adsorption of HCAA resin are attributed to the functional groups - COONa, where the heavy metal ions are chelated with $\mathrm{COO}^{-}$, and the ionized $\mathrm{Na}^{+}$are migrated into the external solution. The adsorption capacity of HCAA resin to $\mathrm{Cr}^{3+}, \mathrm{Cu}^{2+}, \mathrm{Ni}^{2+}$, and $\mathrm{Zn}^{2+}$ was $80.08,158.07,155.71$, and $137.15 \mathrm{mg} / \mathrm{g}$, respectively. The essential adsorption of HCAA resin is to form a coordination bond by sharing the long pair electrons of the active oxygen in $-\mathrm{COO}^{-}$to positive heavy metal ions. And the difference in adsorption capacity to different heavy metal ions is associated with the difference of complexation stability constant between - $\mathrm{COO}^{-}$and heavy metal ions. As an expansive adsorbent for HCAA, this excel- lent performance can speed up the mass transporting rates not only for the heavy metal pollutants but also for the exchanged $\mathrm{Na}^{+}$. The adsorption process for heavy metal pollutants was in line with the Weber-Morris model, where the diffusion of the ionized $\mathrm{Na}^{+}$followed the Fickian diffusion model. Finally, the present work suggests that based on the traditional water- absorbing polymer, increasing the crosslinker contents can gain excellent heavy metal adsorbents.

\section{References}

Ali SL, Khan M, Javed R, Sayed M, Khan MS, Khan A, Ullah M (2018) Superabsorbent polymer hydrogels with good thermal and mechan- ical properties for removal of selected heavy metal ions. J Clean Prod 210:78-87

Almughamisi MS, Khan ZA, Alshitari W, Elwakeel KZ (2020) Recovery of chromium (VI) oxyanions from aqueous solution using $\mathrm{Cu}(\mathrm{OH})_{2}$ and CuO embedded chitosan adsorbents. J Polym Environ 28:47-60

Chen YD (1977) Introduction and analysis of the complexation stability constant. Fudan Univer J4:53-65

Chen YD (1980) Estimation of stability constants of metal complexes. Chem J Chin Univ 1:9-16 
Elgarahy AM, Elwakeel KZ, Mohammad SH, Elshoubaky GA (2020) Multifunctional eco-friendly sorbent based on marine brown algae and bivalve shells for subsequent uptake of Congo red dye and copper (II) ions. J Environ Chem Eng 8:103915

Elwakeel KZ, Shahat A, Al-Bogami AS, Wijesiri B, Goonetilleke A (2020) The synergistic effect of ultrasound power and magnetite incorporation on the sorption/desorption behavior of $\mathrm{Cr}(\mathrm{VI})$ and $\mathrm{As}(\mathrm{V})$ oxoanions in an aqueous system. J Colloid Interface Sci 569:76-88

Fang SX, Wang GJ, Xing RG, Chen XL, Liu S, Qin YK, Li KC, Wang XQ, Li RF, Li PC (2019) Synthesis of superabsorbent polymers based on chitosan derivative graft acrylic acid-co-acrylamide and its property testing. Int J Biol Macromol 132:575-584

Fiyadh SS, AlSaadi MA, Jaafar WZ, AlOmar MK, Fayaed SS, Mohd NS, Hin LS, Shafie AE (2019) Review on heavy metal adsorption pro- cesses by carbon nanotubes. J Clean Prod 230:783-793

Gao XP, Li MY, Zhao YM, Zhang Y (2019a) Mechanistic study of selective adsorption of $\mathrm{Hg}^{2+}$ ion by porous alginate beads. Chem Eng J 378:122096

Gao BQ, Zhang DD, Li YB (2019b) Preparation of PSSS-grafted polysulfone microfiltration membrane and its rejection and removal properties towards heavy metal ions. Polym Adv Technol 30:1096- 1105

Ge HC, Pang W, Luo DK (2006) Graft copolymerization of chitosan with acrylic acid under microwave irradiation and its water absorbency. Carbohydr Polym 66:372-378

Gupta S, Nirwan J (2015) Evaluation of mercury biotransformation by heavy metal-tolerant alcaligenes strain isolated from industrial sludge. Int J Environ Sci Technol 12:995-1002

He GH, Ke WW, Chen X, Kong YH, Zheng H, Yin YH, Cai WQ (2017) Preparation and properties of quaternary ammonium chitosan-g- poly (acrylic acid-co-acrylamide) superabsorbent hydrogels. React Funct Polym 111:14-21

Holyavka MG, Kondratyev MS, Terentyev VV, Samchenko AA, Kabanov AV, Komarov VM, Artyukhov VG (2017) The molecular mechanism of adsorption immobilization of inulinase on polymer matrices. Biophys 62:5-11

Hong TT, Okabe H, Hidaka Y, Omondi BA, Hara K (2019) Radiation induced modified CMC-based hydrogel with enhanced reusability for heavy metal ions adsorption. Polym 181:121772

Hossain MA, Piyatida P, Silva JATD, Fujita M (2012) Molecular mech- anism of heavy metal toxicity and tolerance in plants: central role of glutathione in detoxification of reactive oxygen species and methylglyoxal and in heavy metal chelation. Aust J Bot 2012:1-37

Hu XB (2011) Synthesis and properties of silk sericin- $g$-poly (acrylic acid-co-acrylamide) superabsorbent hydrogel. Polym Bull 66:447-462

Huang XH, Li L, Wang JY, Zhang GZ, Tao XC (2012) Preparation and application of carboxymethyl starch. Appl Mech Mater 268-270: 594-600

Huang ZH, Liu SX, Fang GZ, Zhang B (2013) Synthesis and swelling properties of $\beta$-cyclodextrin-based superabsorbent resin with net- work structure. Carbohydr Polym 92:2314-2320

Jiang CL, Wang XH, Wang GH, Hao C, Li X, Li TH (2019) Adsorption performance of a polysaccharide composite hydrogel based on crosslinked glucan/chitosan for heavy metal ions. Composites B: Eng 169:45-54

Kenawy ER, Azaam MM, El-nshar EM (2019) Sodium alginate-g-poly (acrylic acid-co-2-hydroxyethyl methacrylate)/montmorillonite superabsorbent composite: preparation, swelling investigation and its application as a slow-release fertilizer. Arab J Chem 12:847-856

Kolya H, Das S, Tripathy T (2014) Synthesis of starch- $g$-poly-(N- methylacrylamide-co-acrylic acid) and its application for the

removal of mercury (II) from aqueous solution by adsorption. Eur Polym J 58:1-10

Lan GH, Zhang M, Liu YQ, Qiu HY, Xue SS, Zhang TL, Xu QX (2019) Synthesis and swelling behavior of super-absorbent soluble starch- $g$-poly (AM-co-NaAMC ${ }_{14} \mathrm{~S}$ ) through graft copolymerization and hydrolysis. Starch - Stärke 1800272

Lawson PS, Sterritt RM, Lester JN (1984) Adsorption and complexation mechanisms of heavy metal uptake in activated sludge. J Chem Technol Biotechnol 34:253-262

Li ZX, Wang ZH, Wang CT, Ding SL, Li FW, Lin HF (2019) Preparation of magnetic resin microspheres M-P (MMA-DVB-GMA) and the adsorption property to heavy metal ions. Appl Surf Sci 496:143708

Liu Y, Hu LS, Tan B, Li JR, Gao XH, He YN, Du XF, Zhang W, Wang WL (2019) Adsorption behavior of heavy metal ions from aqueous solution onto composite dextran-chitosan macromolecule resin ad- sorbent. Int J Biol Macromol 141:738-746

Liu QM, Li YY, Chen HF, Lu J, Yu GS, Möslang M, Zhou YB (2020) Superior adsorption capacity of functionalised straw adsorbent for dyes and heavy-metal ions. J Hazard Mater 382:121040

Lu QF, Yu J, Gao JZ, Yang W, Li Y (2012) A promising absorbent of acrylic acid/poly (ethylene glycol) hydrogel prepared by glow- discharge electrolysis plasma. Open Chem 10:1349-1359

Ma ZH, Li Q, Yue QY, Gao BY, Xu X, Zhong QQ (2011) Synthesis and characterization of a novel super-absorbent based on wheat straw. Bioresour Technol 102:2853-2858

Mahdavinia GR, Pourjavadi A, Hosseinzadeh H, Zohuriaan MJ (2004) Modified chitosan 4. Superabsorbent hydrogels from poly (acrylic acid-coacrylamide) grafted chitosan with salt- and pH- responsiveness properties. Eur Polym J 40:1399-1407

Matlock MM, Howerton BS, Atwood DA (2002) Chemical precipitation of heavy metals from acid mine drainage. Water Res 36:4757-4764 Naseem K, Begum R, Wu WT, Usman M, Irfan A, Al-Sehemi AG, Farooqi ZH (2019) Adsorptive removal of heavy metal ions using polystyreneshell gel particles: adsorption isotherms and kinetic study. J Mol Liq 277:522-531

poly(N-isopropylmethacrylamide-acrylic acid) core/

Ni N, Zhang DH, Dumont MJ (2018) Synthesis and characterization of zein-based superabsorbent hydrogels and their potential as heavy metal ion chelators. Polym Bull 75:31-45

Pourjavadi A, Soleyman R, Barajee GR (2008) Novel nanoporous super- absorbent hydrogel based on poly (acrylic acid) grafted onto salep: synthesis and swelling behavior. Starch - Stärke 60:467-475

Shu J, Li XJ, Zhao DB (2011) Microwave-irradiated preparation of super absorbent resin by graft copolymerization of cellulose and acrylic acid/acrylamide. Adv Mater Res 148-149:799-802

Singh T, Singhal R (2012) Poly (acrylic acid/acrylamide/sodium humate) superabsorbent hydrogels for metal ion/dye adsorption: effect of sodium humate concentration. J Appl Polym Sci 125:1267-1283

Soto D, Urdaneta J, Pernía K, León O, Bonilla AM, García MF (2015) Heavy metal $\left(\mathrm{Cd}^{2+}, \mathrm{Ni}^{2+}, \mathrm{Pb}^{2+}\right.$ and $\left.\mathrm{Ni}^{2+}\right)$ adsorption in aqueous solutions by oxidized starches. Polym Adv Technol26:147-152

Tally M, Atassi Y (2016) Synthesis and characterization of pH-sensitive superabsorbent hydrogels based on sodium alginate-gpoly (acrylic acid-coacrylamide) obtained via an anionic surfactant micelle templating under microwave irradiation. Polym Bull 73:3183-3208 
Uddin MK (2017) A review on the adsorption of heavy metals by clay minerals, with special focus on the past decade. Chem Eng J 308: 438-462 Vakili M, Deng SB, Cagnetta G, Wang W, Meng PP, Liu DC, Yu G (2019) Regeneration of chitosan-based adsorbents used in heavy metal adsorption: a review. Sep Purif Technol 224:373-387

Vieira RM, Vilela PB, Becegato VA, Paulino AT (2018) Chitosan-based hydrogel and chitosan/acid-activated montmorillonite composite hydrogel for the adsorption and removal of $\mathrm{Pb}^{2+}$ and $\mathrm{Ni}^{2+}$ ions accommodated in aqueous solutions. J Environ Chem Eng 6:2713-2723

Volkov AG, Paula S, Deamer DW (1997) Two mechanisms of perme- ation of small neutral molecules and hydrated ions across phospho- lipid bilayers. Bioelectrochem Bioenerg 42:153-160

Yu J, Yang GG, Li Y, Yang W, Gao JZ, Lu QF (2014) Synthesis, char- acterization, and swelling behaviors of acrylic acid/carboxymethyl cellulose superabsorbent hydrogel by glow-discharge electrolysis plasma. Polym Eng Sci 54:2310-2320

Zhang M, Lan GH, Qiu HY, Zhang TL, Li WJ, Hu XQ (2019) Preparation of ion exchange resin using soluble starch and

acrylamide by graft polymerization and hydrolysis. Environ Sci Pollut Res 26:3803-3813

Zhao BC, Jiang HB, Lin ZK, Xu SF, Xie J, Zhang AP (2019) Preparation of acrylamide/acrylic acid cellulose hydrogels for the adsorption of heavy metal ions. Carbohydr Polym224:115022

Zou XY, Zhao YB, Zhang ZJ (2019) Preparation of hydroxyapatite nano- structures with different morphologies and adsorption behavior on seven heavy

metals

ions.

$\mathrm{J}$

Contam

Hydrol

226:10353 
